\title{
Antimony recovery from lead-rich dross of lead smelter and conversion into antimony oxide chloride $\left(\mathrm{Sb}_{4} \mathrm{O}_{5} \mathrm{Cl}_{2}\right)$
}

\author{
Thupten Palden ${ }^{\dagger \ddagger}$, Lieven Machiels ${ }^{\dagger \ddagger}$, Mercedes Regadío ${ }^{\dagger}$, Koen Binnemans ${ }^{\dagger *}$
}

${ }^{\dagger}$ KU Leuven, Department of Chemistry, Celestijnenlaan 200F, P.O. box 2404, B-3001 Leuven, Belgium.

‡SIM vzw, Technologiepark 935, B-9052 Zwijnaarde, Belgium.

*Corresponding author:

Email: Koen.Binnemans@kuleuven.be

\section{Supporting information}

Total number of pages: 7 (S1-S7)

Total number of figures: 6 (Figure S1-S6) 
Supporting information
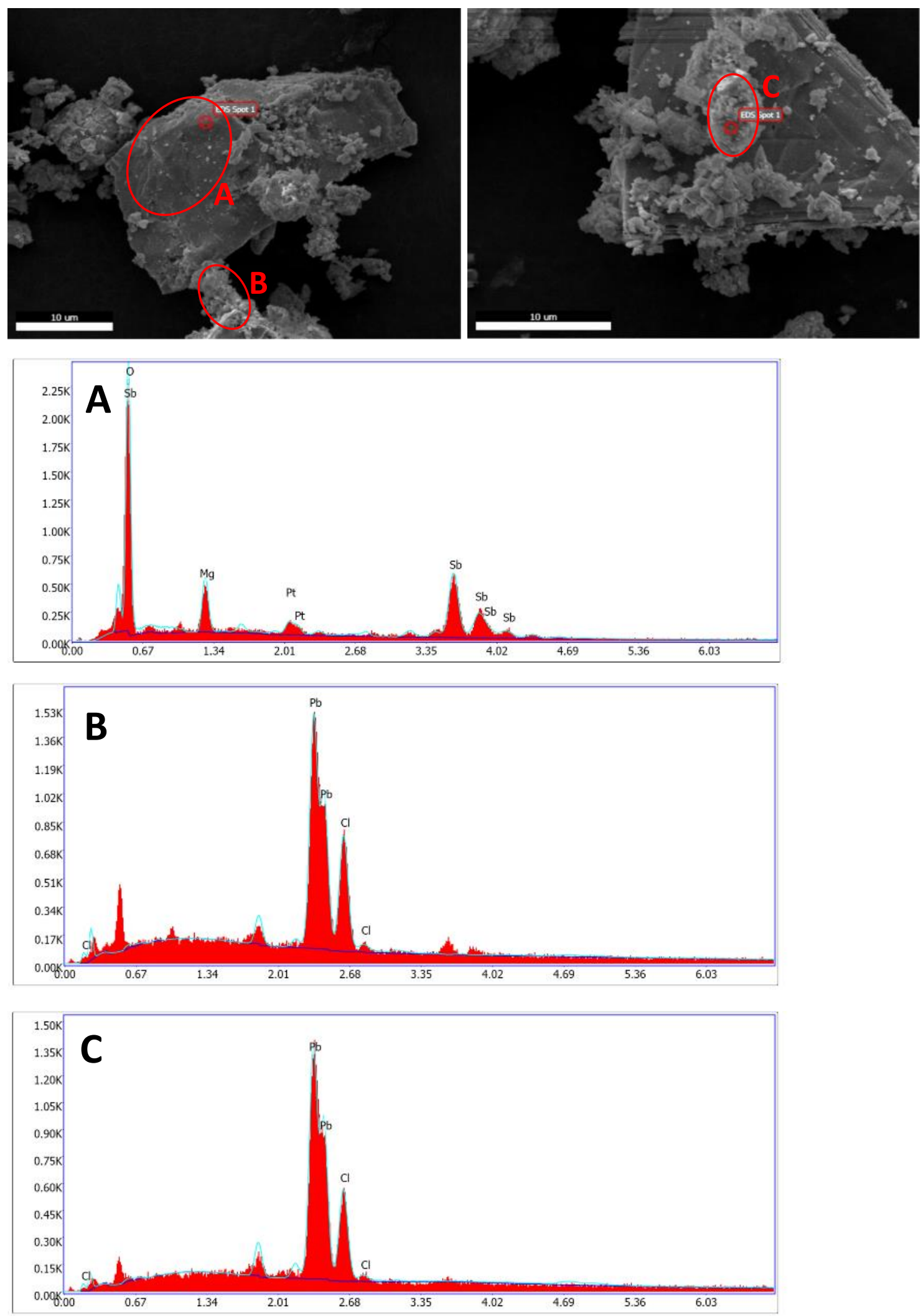

Figure S1: SEM micrographs and corresponding EDS spectra of particles from the leach residue of leaching dross1 using $2 \mathrm{~mol} \mathrm{~L}^{-1}$ hydrochloric acid in ethanol. 


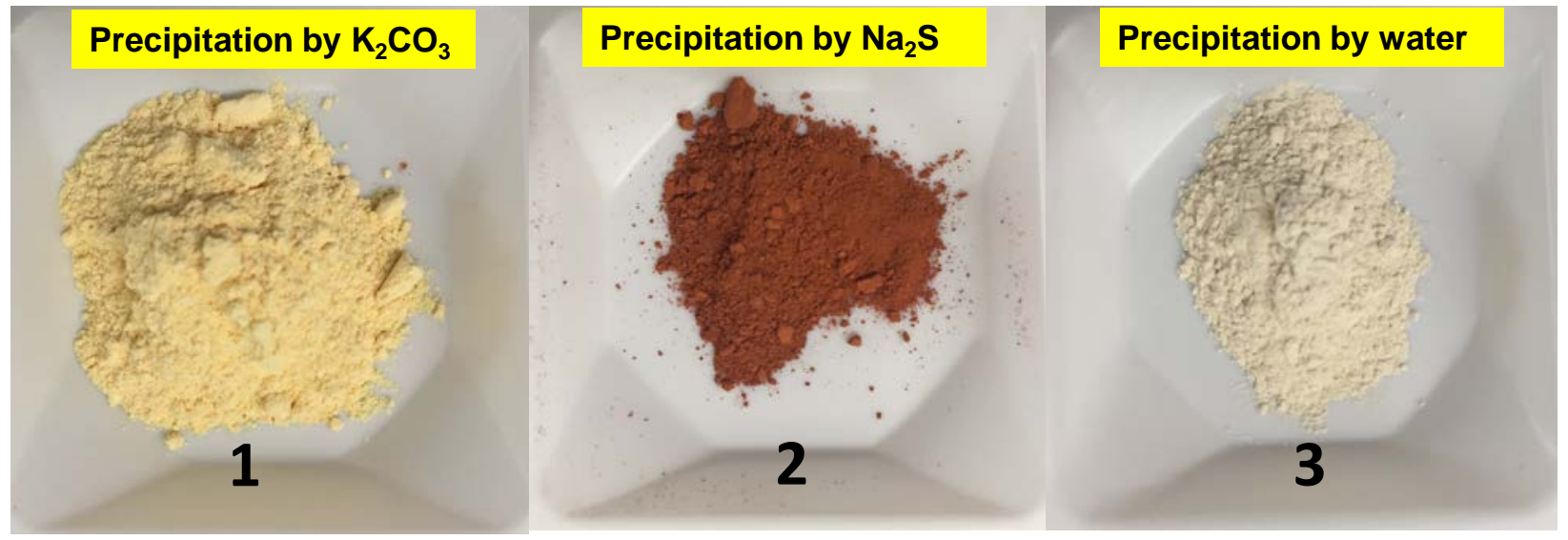

Figure S2: Photographs of precipitates formed after addition of: 1) potassium carbonate, 2) sodium sulfide and 3) water to the pregnant leach solution after leaching dross 1 with 2 mol L-1 hydrochloric acid in ethanol. 

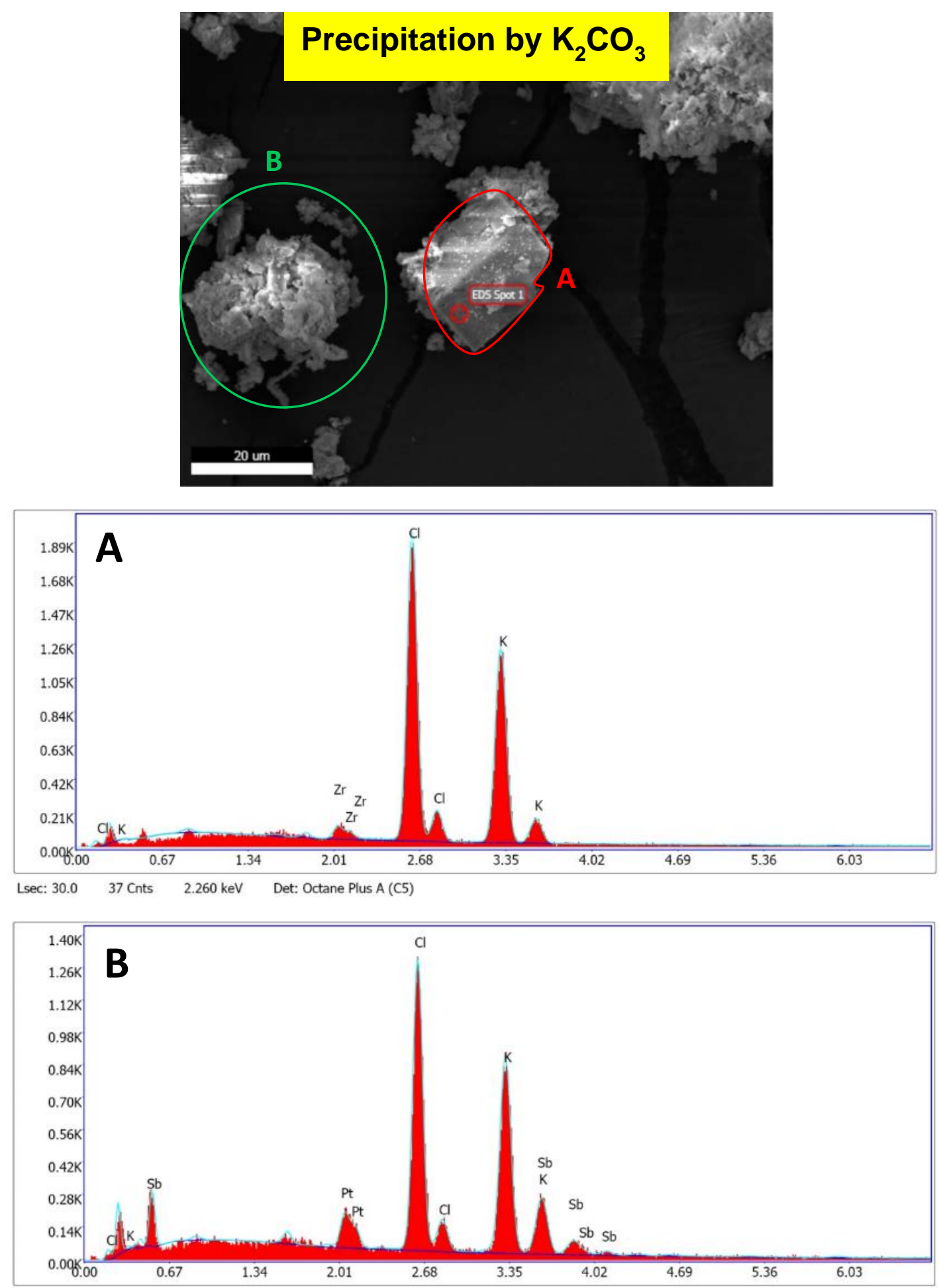

Figure S3: SEM micrographs and corresponding EDS spectra of particles from the precipitates formed after addition of potassium carbonate to the pregnant leach solution of leaching dross1 using $2 \mathrm{~mol} \mathrm{~L}^{-1}$ hydrochloric acid in ethanol. 

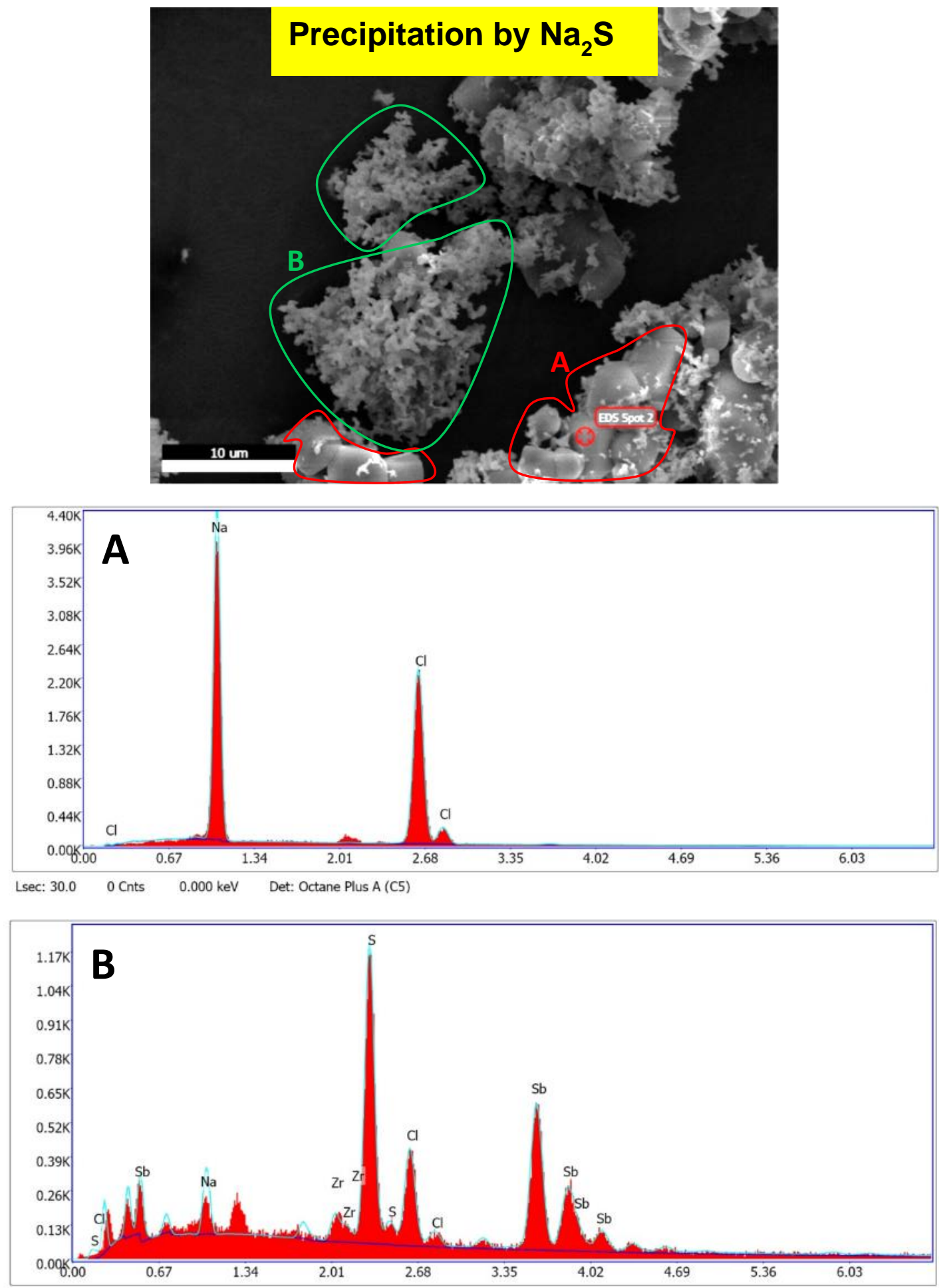

Figure S4: SEM micrographs and corresponding EDS spectra of particles from the precipitates formed after addition of sodium sulfide to the pregnant leach solution of leaching dross1 using 2 mol L ${ }^{-1}$ hydrochloric acid in ethanol. 

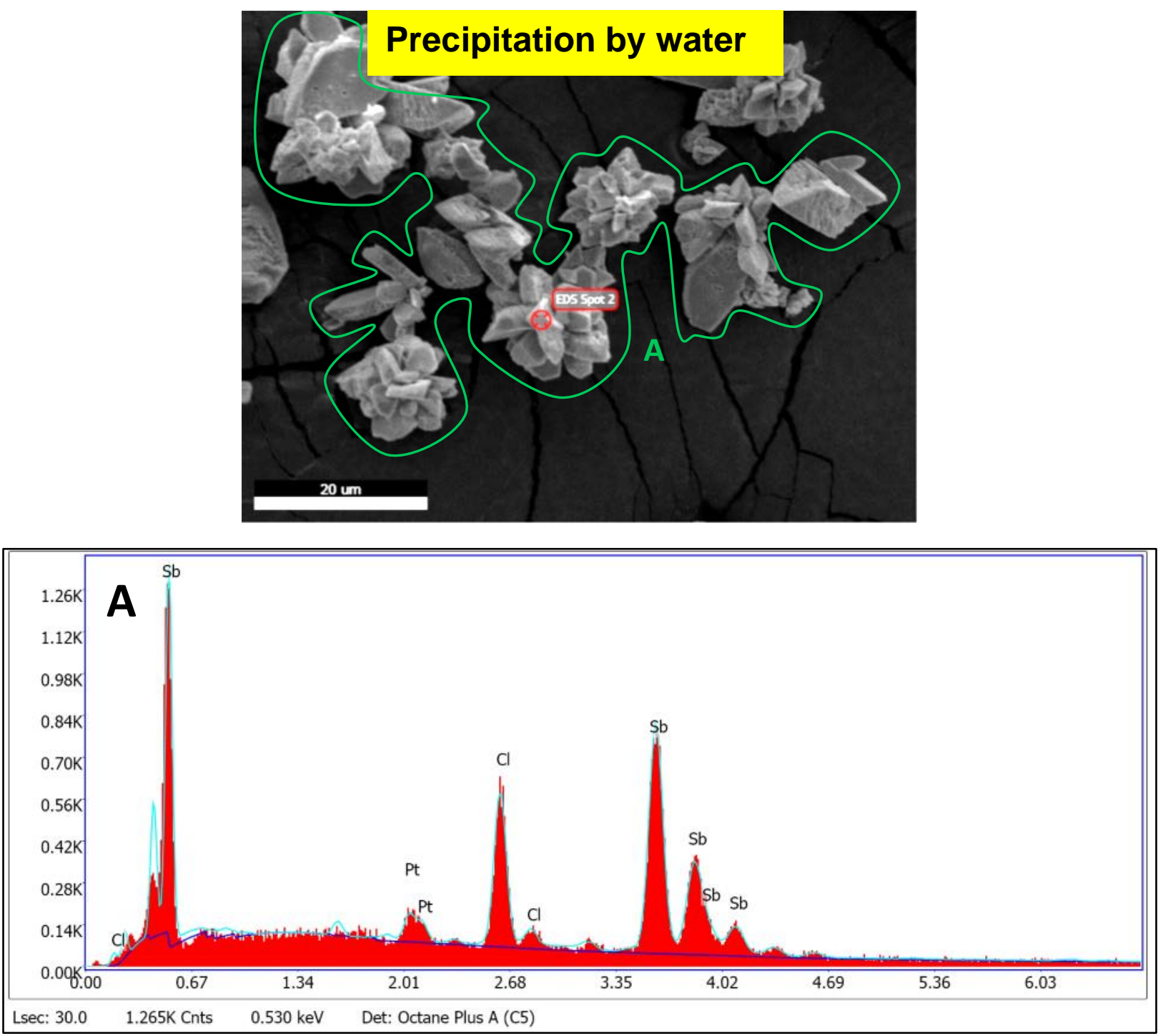

Figure S5: SEM micrographs and corresponding EDS spectra of particles from the precipitates formed after addition of water to the pregnant leach solution of leaching dross 1 using $2 \mathrm{~mol} \mathrm{~L}^{-1}$ hydrochloric acid in ethanol. 
Supporting information

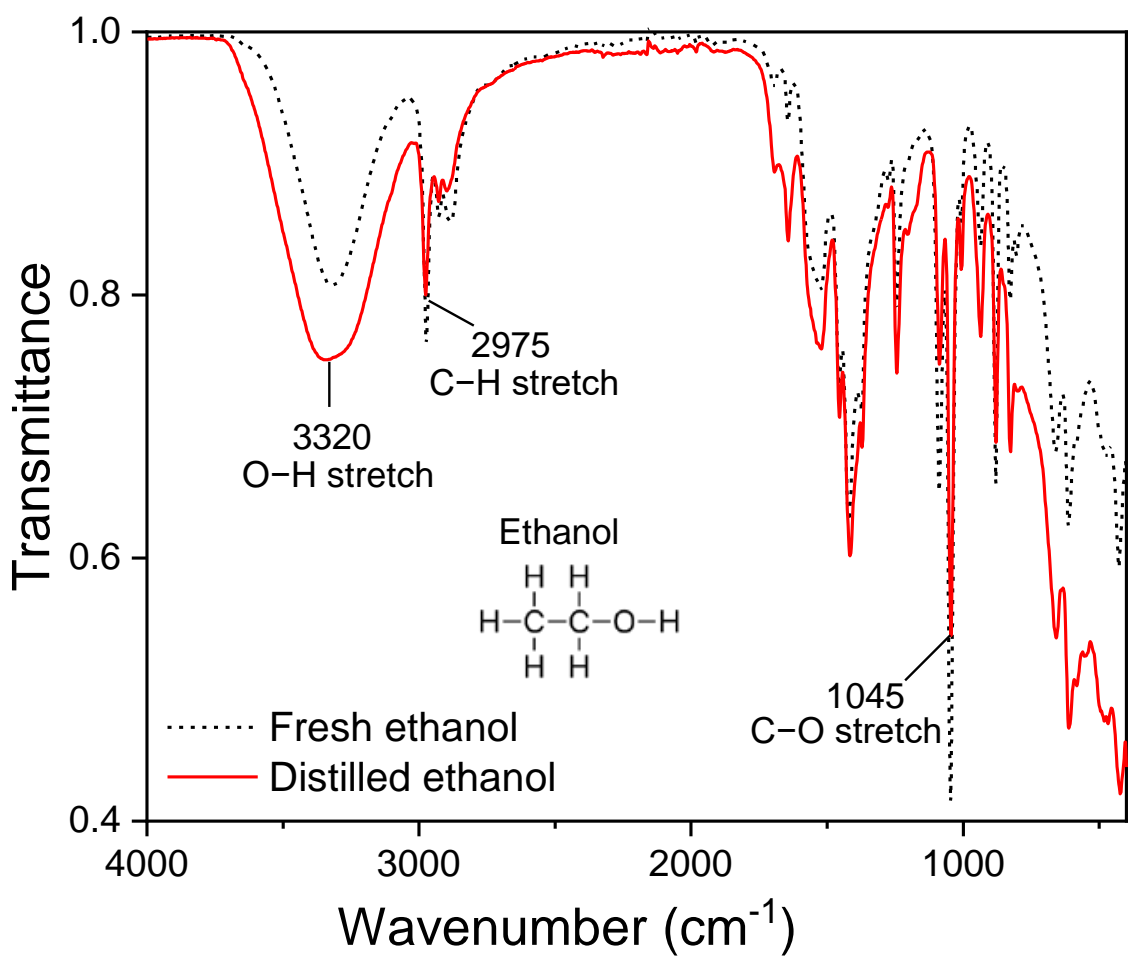

Figure S6: FTIR spectra of fresh ethanol and distilled ethanol. 